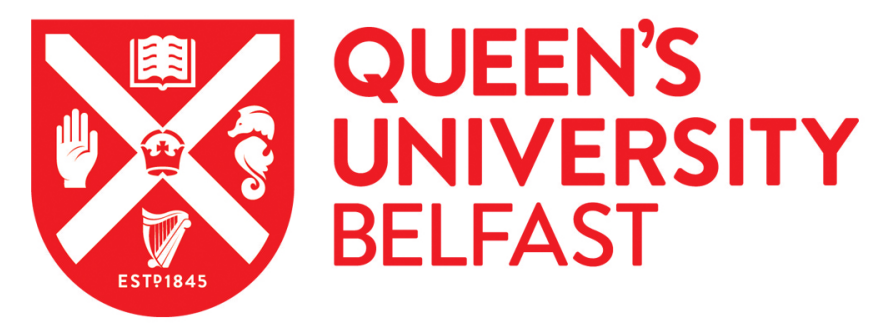

\title{
Feasibility of a standardised quality of life questionnaire in a weekly diary format for inoperable lung cancer patients
}

Mills, M., Murray, L., Johnston, B. T., \& Donnelly, M. (2008). Feasibility of a standardised quality of life questionnaire in a weekly diary format for inoperable lung cancer patients. European Journal of Oncology Nursing, 12(5), 457-463. https://doi.org/10.1016/j.ejon.2008.06.003

Published in:

European Journal of Oncology Nursing

Queen's University Belfast - Research Portal:

Link to publication record in Queen's University Belfast Research Portal

\section{General rights}

Copyright for the publications made accessible via the Queen's University Belfast Research Portal is retained by the author(s) and / or other copyright owners and it is a condition of accessing these publications that users recognise and abide by the legal requirements associated with these rights.

Take down policy

The Research Portal is Queen's institutional repository that provides access to Queen's research output. Every effort has been made to ensure that content in the Research Portal does not infringe any person's rights, or applicable UK laws. If you discover content in the Research Portal that you believe breaches copyright or violates any law, please contact openaccess@qub.ac.uk. 


\title{
Feasibility of a standardised quality of life questionnaire in a weekly diary format for inoperable lung cancer patients
}

\author{
Moyra E. Mills ${ }^{\mathrm{a}, *}$, Liam J. Murray ${ }^{\mathrm{a}}$, Brian T. Johnston ${ }^{\mathrm{b}}$, Michael Donnelly ${ }^{\mathrm{a}}$ \\ ${ }^{a}$ Cancer Epidemiology and Prevention Research Group, Centre for Clinical and Population Sciences, Queen's University, Belfast, \\ Mulhouse Building, RGH Site, Grosvenor Road, Belfast BT12 6BJ, Northern Ireland \\ ${ }^{\mathrm{b}}$ Royal Group of Hospitals, Grosvenor Road, Belfast BT12 6BA, Northern Ireland
}

Keywords:

Quality of life

Diary format

Feasibility

Lung cancer

Palliative care

\begin{abstract}
A B S T R A C T
Objective: Previous studies testing quality of life assessment (QoL) in routine oncology clinical practice have been based at single institutions and many have utilised touch-screen computer technology. The objective of this study was to test the feasibility of a low-tech QoL diary that could be held by the patient and shared with professionals across the health care setting.

Methods: The EORTC-QLQ-C30 and LC13 were used and adapted into an A5 diary format. Patients were instructed to complete the questions each week at home and to share the information with any health professional involved in their care. Feasibility of the diary format was examined through assessment of compliance, utilisation and satisfaction using a mixed methods approach.

Results: Diary completion rates were good; however, utilisation of the diary was poor, with only $23 \%$ $(13 / 57)$ of patients stating explicitly that they had shared the diary with a health professional. Patients were generally satisfied with the diary format; however, qualitative analysis did identify some negative effects of diary completion.

Conclusions: A patient-held QoL diary is feasible for a proportion of palliative care patients but the importance of training and support for patients and staff cannot be underestimated when implementing a new tool into clinical practice.
\end{abstract}

(c) 2008 Elsevier Ltd. All rights reserved.

\section{Introduction}

In recent years there have been a number of randomised controlled trials, which have investigated the use of quality of life (QoL) measures in routine oncology clinical practice. The results of these studies, while not conclusive, suggest that the implementation of standardised QoL instruments in clinical practice may benefit patient care in a number of ways (see Table 1 ).

In order for a QoL assessment to be used in routine clinical practice it needs to be clinically relevant, sensitive to change, low cost, low burden and easily incorporated without disrupting the clinical routine (Perry et al., 2007). As the EORTC-QLQ-C30 and its associated modules appear to meet these implementation criteria, they have been successfully utilised in studies of QoL assessment in clinical practice (Detmar et al., 2002; Velikova et al., 2004). However, most studies in clinical practice have evaluated touchscreen technology at hospital-based clinics and while reporting positive findings it has to be recognised that this is a costly method that has not extended outside the hospital setting. In contrast,

\footnotetext{
* Corresponding author. Tel.: +44 289063 5059/2746; fax: +44 2890631907. E-mail address: mmills05@qub.ac.uk (M.E. Mills).
}

a 'low-tech' method that is affordable and can be implemented across health care settings and institutions has not been evaluated. This could potentially be achieved through adapting the EORTCQLQ-C30 and LC13 into a diary format.

QoL data have previously been collected in a diary format to measure longitudinal change in patients (Hyland and Crocker, 1995), diaries can be successfully implemented with lung cancer patients (Geddes et al., 1990; Ishihara et al., 1999) and they are suitable for patients with palliative or advanced cancer (Hoekstra et al., 2004; Maunsell et al., 2000). Advantages of the diary format are that participants have reported enjoying the experience of keeping a diary (Milligan et al., 2005), using it as a tool for gaining knowledge about their condition, consolidating memory, monitoring change, selfreflection and as a communication device to facilitate doctor-patient communication (Reid et al., 2003). In addition patients can complete their diary at home, which minimises any possible positive or negative influence from health care professionals (Andersen et al., 2006).

\section{Study aims}

This study aimed to explore the feasibility of implementing the EORTC-QLQ-C30 and LC13 as a patient-held QoL diary in routine 
Table 1

Proposed benefits of QoL measurement in clinical practice.

- Improved identification, prioritisation and monitoring of problems, thus allowing earlier intervention (Detmar et al., 2002; Mazonson et al., 1996; McLachlan et al., 2001; Rubenstein et al., 1995; Velikova et al., 2004).

- Facilitation of communication regarding the problems identified in the measure acting as a stimulus for the health care interaction (Detmar et al., 2002; Taenzer et al., 2000; Velikova et al., 2004).

- Monitoring change in symptoms over time or response to treatment (Boyes et al., 2006).

- Improvements in the process of care through identifying patient preferences, promoting shared decision making and increasing referral rates to other services, thus improving the delivery of care (Detmar et al., 2002; Espallargues et al., 2000; Mazonson et al., 1996; Rubenstein et al., 1995).

- Improvement in QoL (Velikova et al., 2004).

- An important prognostic factor for survival, whereby QoL has been shown to be a more accurate predictor of length of survival than traditional clinical indicators eg. performance status and blood counts (Efficace et al., 2004, 2006; Ganz et al., 1991; Montazeri et al., 2001; Osoba, 1999).

- Increased satisfaction with care (Detmar et al., 2002)

clinical practice for patients with inoperable lung cancer. This paper reports on patients' compliance, utilisation, satisfaction and experience of completing their diary each week for 16 weeks.

\section{Methods}

\section{Patients}

Patients were recruited from outpatient clinics at the Cancer Centre (Belfast City Hospital) and two of the four cancer units in Northern Ireland (Antrim Hospital and Altnagelvin Hospital). Eligibility criteria comprised a clinical diagnosis of inoperable lung cancer, able and willing to give written informed consent, a WHO performance status of 0-2 and no cognitive impairment or learning disability.

The study was approved by local Research Ethics Committees and Research Governance was granted by each hospital. Senior medical staff initially assessed patients in terms of the eligibility criteria; they introduced the study to patients and ascertained whether or not they would be willing to speak to the researcher. Patients who agreed to speak to the researcher were given a detailed verbal description of the study and a written information sheet to take home in order to consider the study further and to discuss it with their family and friends. The researcher contacted patients at home approximately 48 hours later and confirmed whether or not they were willing to participate. Once written informed consent was gained they were randomised to receive a patient-held QoL diary or standard care.

\section{Study design}

A mixed methods approach was used to evaluate the implementation, feasibility and perceived value of using a QoL diary by quantitatively assessing response rates, missing data and patient satisfaction in conjunction with collecting qualitative data from a subgroup of patients on their views and experiences of completing the diary. The evaluation took place in the context of a larger randomised controlled trial designed to test the effectiveness of the QoL diary.

\section{Intervention}

The intervention involved the completion of a QoL questionnaire in the form of a diary each week for 16 weeks. The questionnaire content was unchanged from the original EORTCQLQ-C30; however, the layout was adapted, with permission from the EORTC Quality of Life group, to suit an A5 diary format, with each booklet containing four questionnaires. In addition a page was inserted after each questionnaire asking if the QoL information had been discussed with any health care professional during that week. Patients were encouraged to share their diary with all health care professionals. A new diary was posted to the patient each month with a self-addressed envelope in which the previous diary could be returned to the researcher via mail or at their next hospital appointment.

EORTC-QLQ-C30 is a 30 -item questionnaire comprising five functional scales (physical, role, emotional, cognitive and social), three symptom scales (fatigue, pain and nausea/vomiting), a global QoL scale and six single items on cancer-associated symptoms and the perceived economic impact of disease and treatment. The QLQ-LC13 is a supplementary, 13-item lung cancer specific module. Both the QLQC30 and LC13 have been validated in large international studies (Bergman et al., 1994), they have been tested in the palliative care setting (Nicklasson and Bergman, 2007; Hicsonmez et al., 2007), are sensitive to change over time (Hjermstad et al., 1995) and are relatively short and easy to complete, taking approximately 10 minutes.

\section{Outcomes and analysis}

Patient compliance was assessed, monthly in terms of calculating the percentage completion rates for each patient, the amount, frequency and nature of missing data and reasons for noncompletion were also assessed and descriptive analysis carried out. Associations between completion rates, age, gender, marital status and social status were tested using non-parametric tests.

A structured questionnaire was administered at the end of month two and four to assess utilisation of the diary and satisfaction with the tool. The questionnaire content was subjected to descriptive analysis. The questionnaire was adapted, with permission, from Velikova's et al. (2002) study where it had been used to assess the use of computer based QoL questionnaires at medical oncology clinics.

Qualitative data were collected from optional free-text sections at the end of each diary and each questionnaire and from seven semi-structured interviews, involving four women and three men with an age range of 50-75 years. The number of interviews was limited by the rapid disease progression in this patient group, whereby many of those who completed the intervention were not sufficiently well to be approached for interview. Content analysis was used to identify themes that emerged from these data.

\section{Results}

\section{Participants}

Fifty-seven patients were recruited and randomised to receive the diary intervention. Table 2 details the baseline characteristics of the patient group, with the majority of participants being males (60\%), aged $61-80$ years (61\%) and having a diagnosis of non-small cell lung cancer (79\%).

\section{Compliance}

Fig. 1 depicts the proportion of patients each month that completed $100 \%, 75-99 \%, 50-74 \%,<50 \%$ and none of the dairy. Patients who completed 75-99\% of their diary each month generally missed a few random questions or entire pages through error. No individual questions were routinely omitted by patients. Patients who completed 50-74\% omitted entire weeks because they were unwell and many then recommenced their diary. The three 
Table 2

Baseline characteristics of participants.

\begin{tabular}{lcr}
\hline & $n=57$ & $\%$ \\
\hline Age group & 5 & 9 \\
$<50$ years & 16 & 28 \\
$51-60$ & 18 & 31 \\
$61-70$ & 17 & 30 \\
$71-80$ & 1 & 2 \\
$80+$ years & & \\
Gender & 34 & 60 \\
Male & 23 & 40 \\
Female & & 79 \\
Diagnosis & 45 & 17 \\
NSCLC & 10 & 4 \\
SCLS & 2 & 23 \\
Mesothelioma Unknown primary & & 56 \\
WHO & & 21 \\
0 & 13 & \\
1 & 32 & \\
2 & 12 & \\
\hline
\end{tabular}

a World Health Organisation, performance status.

middle groupings of patients account for a relatively small proportion of patients. The percentage of patients who did not complete any of their diary increased from $23 \%(n=13)$ in month one to $49 \%(n=28)$ at month four. Reasons for non-completion are summarised in Table 3. During month one, of the five patients who were too unwell to complete their diaries, two recovered significantly following their initial treatment regime and were able to complete subsequent diaries.

Non-parametric analysis indicated that there were not any significant differences in completion rates related to age, gender, marital status and social status (lives alone or with family) (see Table 4).

\section{Utilisation and satisfaction with the diary}

As presented in Table 5, most respondents were satisfied with the diary. The first four questions related to patients' general satisfaction with the diary format. The majority of patients responded positively at both time points on this aspect: Eightyseven percent indicated that the diary was asking the right questions, over $90 \%$ stated that there were no upsetting or distressing questions and 89 and $90 \%$ at months two and four, respectively, agreed that the time spent completing the diary was acceptable. In relation to irrelevant questions, a higher proportion of patients noted some dissatisfaction with this aspect of the questionnaire. The next four questions related to the utilisation of the diary. Two questions were answered consistently over the two time periods with just over $60 \%$ of patients agreeing that it was useful to complete and use the diary to inform the health care team how

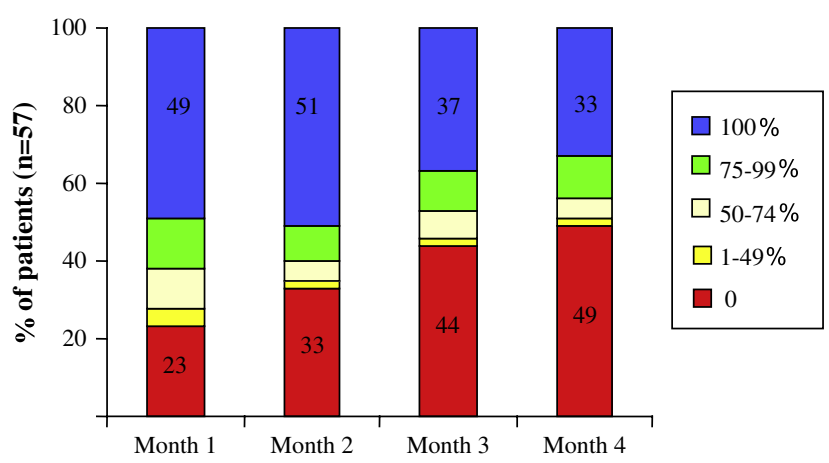

Fig. 1. Proportion of patients completing their diary each month.
Table 3

Reasons for non-completion of QoL diaries.

\begin{tabular}{llrrrrr}
\hline Reason for not completing diary & \multicolumn{2}{l}{ Month 1} & & \multicolumn{2}{c}{ Month 4} \\
\cline { 2 - 3 } & $n=57$ & & & $n=57$ & $\%$ \\
\hline Deceased & 3 & 5 & 8 & 14 \\
Withdrew or too unwell to complete diary & 8 & 14 & & 14 & 25 \\
No reason available & 3 & 5 & 6 & 11 \\
\hline
\end{tabular}

they felt and approximately $80 \%$ stated that the health care team did consider their QoL when advising them. Over $80 \%$ of patients also indicated that they considered it appropriate to include these types of questionnaires in routine care. Two questions in this section showed a change from the two- to four-month assessment. The proportion of patients who indicated that they discussed the diary with the health care team was low; however, it did increase from the month two to month four assessments (see Fig. 2). Of the five patients (16\%) at month two who indicated that they had discussed the diary with the health care team, one had withdrew by month four, one was unsure if he had discussed the diary information again with a health professional, one indicated that he had not discussed the diary information between months two and four and only two patients indicated at month four that they still shared the diary with health professionals. Thus six additional patients at month four indicated that they were now sharing the diary information with health care professionals. A slight increase was also noted in relation to the discussion of the diary with family and friends. Again this included an additional six patients who previously indicated that they had not discussed the diary information with family/friends. Two of these patients matched with those that had started to share the diary with health professionals during the latter part of the study.

\section{Qualitative data from intervention patients}

\section{Sharing the diary with health professionals}

Participants gave a number of reasons for not sharing their diaries. The experience of no-one asking for the diary and no health care staff calling to see patients in their own home was described by a number of patients at interview and in free-text sections. In addition some patients stated that they forgot to take the diary or they were able to tell the health care team how they felt without using the diary. Although patients did not share their diary, three

\section{Table 4}

Associations between completion rates and age, gender, marital status and social status.

\begin{tabular}{lrll}
\hline & $n$ & Median completion rate & $p$ \\
\hline Age group & 5 & 94 & $0.43^{\mathrm{a}}$ \\
$<50$ & 16 & 64 & \\
$51-60$ & 18 & 53 & \\
$61-70$ & 18 & 71 & $0.71^{\mathrm{b}}$ \\
$71+$ & & & \\
Gender & 34 & 75 & $0.57^{\mathrm{a}}$ \\
$\quad$ Male & 23 & 64 & \\
Female & & & \\
Marital status & 36 & 69 & \\
$\quad$ Married & 6 & 41 & \\
$\quad$ Separated & 5 & 67 & \\
Single & 9 & 92 & \\
$\quad$ Widowed & & & \\
Social status & 44 & 67 & \\
$\quad$ Lives with family & 13 & 86 & \\
$\quad$ Lives alone & & & \\
\hline
\end{tabular}

a Kruskal-Wallis test used for comparing distribution in four groups.

b Mann-Whitney $U$ test used for comparing distribution in two groups. 
Table 5

Patient satisfaction and utilisation of the QoL diary.

\begin{tabular}{|c|c|c|c|}
\hline & & Month two & Month four \\
\hline & & $\%(n)$ & $\%(n)$ \\
\hline \multicolumn{4}{|l|}{ Patient satisfaction } \\
\hline \multirow{3}{*}{$\begin{array}{l}\text { Was the diary asking the right } \\
\text { questions? }\end{array}$} & Yes & $87(32)$ & 87 (27) \\
\hline & Not sure & $13(5)$ & $10(3)$ \\
\hline & No & & $3(1)$ \\
\hline \multirow{3}{*}{$\begin{array}{l}\text { Were there any irrelevant } \\
\text { questions? }\end{array}$} & Yes & $26(9)$ & $33(10)$ \\
\hline & Not sure & 31(11) & $39(12)$ \\
\hline & No & $43(15)$ & $28(9)$ \\
\hline \multirow{3}{*}{$\begin{array}{l}\text { Were there any questions } \\
\text { that were upsetting or distressing? }\end{array}$} & Yes & $6(2)$ & $6(2$ \\
\hline & Not sure & $3(1)$ & \\
\hline & No & $91(32)$ & $94(29)$ \\
\hline \multirow{3}{*}{$\begin{array}{l}\text { Was the time spent completing } \\
\text { the diary acceptable? }\end{array}$} & Yes & $89(33)$ & $90(28)$ \\
\hline & Not sure & $8(3)$ & $10(3$ \\
\hline & No & $3(1)$ & \\
\hline \multicolumn{4}{|l|}{ Utilisation } \\
\hline \multirow{3}{*}{$\begin{array}{l}\text { Was the information in the } \\
\text { diary discussed with family/friends? }\end{array}$} & Yes & $46(17)$ & 61 (19) \\
\hline & Not sure & $3(1)$ & $3(1)$ \\
\hline & No & $51(19)$ & $36(11)$ \\
\hline \multirow{3}{*}{$\begin{array}{l}\text { Was the information in the } \\
\text { diary discussed with the } \\
\text { health care team? }\end{array}$} & Yes & $16(5)$ & $30(8)$ \\
\hline & Not sure & & $7(2)$ \\
\hline & No & $84(26)$ & $63(17)$ \\
\hline \multirow{3}{*}{$\begin{array}{l}\text { Was it useful to complete the } \\
\text { diary to tell the health care } \\
\text { team how you felt physically } \\
\text { and emotionally? }\end{array}$} & Yes & $61(20)$ & $63(19)$ \\
\hline & Not sure & $18(6)$ & $27(8)$ \\
\hline & No & $21(7)$ & $10(4)$ \\
\hline \multirow{3}{*}{$\begin{array}{l}\text { Did the health care team } \\
\text { consider your overall quality } \\
\text { of life when advising you? }\end{array}$} & Yes & $78(26)$ & $81(25)$ \\
\hline & Not sure & $19(6)$ & $16(5)$ \\
\hline & No & $3(1)$ & $3(1)$ \\
\hline \multirow{3}{*}{$\begin{array}{l}\text { Is it appropriate to include } \\
\text { these types of questionnaires } \\
\text { in routine care? }\end{array}$} & Yes & $81(30)$ & $87(27)$ \\
\hline & Not sure & $16(6)$ & $10(3)$ \\
\hline & No & $3(1)$ & $3(1)$ \\
\hline
\end{tabular}

patients suggested that it did help them to ask the 'right' questions. In contrast three other patients didn't feel it was beneficial in this way as they felt capable of asking appropriate questions or they felt the doctors were so thorough that additional questions were not required.

\section{Focus on feelings}

Interviewees were asked about the extent to which completing the diary made them focus on how they were feeling and whether or not this had a beneficial or negative impact. Two patients were certain that it did make them think more about how they were feeling and that this was beneficial. Two interviewees stated that they "didn't think too much about it". Another two patients expressed some negative views on this aspect. One described it as, 'sometimes a good thing, sometimes a bad thing' to think about how you were feeling. Another patient while recognising some benefits to completing the diary also expressed a negative aspect in that the

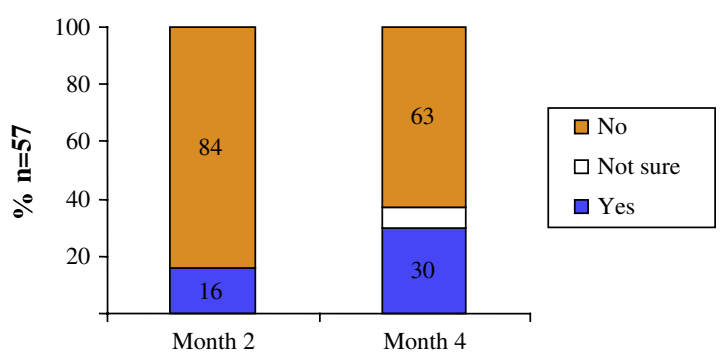

Fig. 2. Proportion of patients who discussed their QoL diary with the health care team. diary drew attention to his illness, which he stated he often tried to ignore.

\section{General comments}

Most general comments about the diary were positive statements. These included comments on it being easy to complete or that it allowed the participant to chart their progress or to see how they had coped over the four-week period. A few negative aspects were also identified such as the repetitive nature of the diary. In addition, a relative also commented that their family member "didn't really enjoy filling them in - perhaps because he knew that he wasn't going to get better."

\section{Discussion}

\section{Attrition rate}

The attrition rate was high though comparable to similar studies. Just under half of the patients (48\%) completed all outcome measures over the four-month study period. A further $21 \%$ completed two of the outcome assessments, which increased the overall data available for statistical analysis. High attrition rates are commonplace in this type of research (Bottomley et al., 2003) with previous studies in palliative care settings finding that only $44 \%$ of patients completed all study procedures (Ling et al., 2000) and attrition rates of $47 \%$ occurred at some recruitment sites in a large American lung cancer study (Cooley et al., 2003). The main reasons for not completing assessments were death or deterioration in health and again this concurs with other research in this area.

\section{Utilisation of diary}

Utilisation of the diary was poor with only $23 \%$ (13/57) of patients stating explicitly that they shared the actual diary with a health professional. The qualitative interviews offered some reasons why this may have occurred.

A number of patients stated that 'no-one asked for the diary'. This is not unusual when implementing a new tool into routine practice (Lecouturier et al., 2002) and a similar study that implemented electronic recording of symptoms at chemotherapy clinics found that the most common barrier to adherence was that staff failed to remind patients to use the system (Basch et al., 2007). Although both community and hospital staff were aware that this study was ongoing and that patients had diaries which they were encouraged to share with them, it was not stipulated that they should ask patients for their diary. The few studies of the implementation of QoL measures at medical outpatient clinics (Detmar et al., 2002; Velikova et al., 2004; Wright et al., 2003), which have reported positive findings, have been implemented within one hospital and the clinicians involved received specific training and regular updates on the use of QoL measures. The importance of training staff has been highlighted in a number of recent papers (Frost et al., 2007) and reviews (Haywood et al., 2006) and it would appear perhaps unsurprisingly that staff training tends to increase the likelihood of achieving the successful implementation of QoL measures in clinical practice (Velikova et al., 2007).

Training alone may not be sufficient to ensure the implementation and use of QoL instruments in clinical practice (Greenhalgh et al., 2005). It may be necessary also to regularly encourage staff to use the QoL data. Indeed, there may be some merit in encouraging a clinician within the clinical setting to 'champion' the integration of QoL assessment, that is to encourage the use, reinforce the worth and overcome potential problems to implementation. This idea has been proposed as a means of overcoming some of the barriers to implementing QoL assessment into clinical practice (Frost et al., 2007). It is a concept that appears most 
frequently in USA health care and it has been used in a variety of health care settings to aid the successful implementation of new initiatives and guidelines (Ouslander, 2007; Roth et al., 2007; Schachter and Cohen, 2005; Shafer et al., 2002).

Another potential clinician-related barrier is that clinicians may feel that they do not have the skills to address some of the issues (e.g. psychological problems) that patients may identify in QoL questionnaires and that there is a responsibility to address identified needs. This lack of confidence in dealing with QoL issues has been highlighted as a barrier in other studies (Frost et al., 2007; Hahn and Cella, 2003; Morris et al., 1998) although there is no evidence in this study to confirm that clinicians were intentionally refraining from asking for a patient's diary.

It is possible that a perceived lack of interest from the clinicians may have deterred patients from sharing diary information. This has been identified as a problem in other research whereby poor utilisation of symptom reporting was associated with a perception among the participants that the information was not being explicitly addressed by the clinicians (Basch et al., 2007). A prerequisite to patient utilisation of an intervention in clinical practice is the perception that the intervention is of interest or can be used by the clinicians involved in that patient's care.

\section{Reluctance by patient to share the information}

Patient related issues may also have limited the utilisation of the diary. Previous work suggests that the type of information patients want to discuss or share with the health care team is variable. One study found that while almost all patients were happy to discuss physical problems, only $25 \%$ wanted to discuss emotional problems if they are initiated by the doctor and $20 \%$ of patients did not want to discuss family and social life with their doctor at all (Detmar et al., 2000). As the diary covered all aspects of QoL it is possible that some patients may not have wished to discuss the more personal aspects of their QoL, such as family relationships, and as a result did not share the diary with the health care team. There is also the potential problem that the word 'diary' connotes a personal record and that this view could have increased the reluctance among patients to share their diary information.

\section{Did not bring the diary to clinic visits}

Another reason for not using the diary was that some patients simply did not take the diary with them to appointments with health care professionals. This reason has featured in previous work looking at the utilisation of a patient-held record for lung cancer patients whereby $36 \%$ of patients did not offer their record to professionals and gave no particular reason for this action (Lecouturier et al., 2002). Some patients in this study stated that they forgot to bring their diary, which is understandable as many patients find attending oncology outpatient clinics a stressful event especially when they are receiving treatment or results on their progress.

\section{Lack of opportunity to share the diary}

Several patients highlighted that apart from their hospital consultant they had little or no contact with other health care staff. It is thus possible that some participants may not have shared their diary because of a lack of opportunity to do so rather than a lack of willingness. This problem has been identified by other researchers (Lecouturier et al., 2002).

\section{Trust in health care staff}

Some participants stated that they had considerable trust in the hospital consultant to ask the right questions and one participant described their consultant as being "so thorough" that there was no need to supply additional information. This view was supported by a question in the Diary Satisfaction Questionnaire, whereby 78\% and $81 \%$ of patients at month two and four respectively, indicated that their health professionals did consider their QoL when advising them. Thus, it may be that health care professionals asked appropriate questions about QoL regularly and as a result patients did not feel that the diary was needed.

Closely linked with trust is familiarity. The health care system in Northern Ireland is relatively small and there is generally little migration of patients or senior health care staff. As a result staff and patients get to know each other fairly well, and as reported elsewhere (Frost et al., 2007), this familiarity may mean that information from QoL instruments may not offer much added value.

A combination of these factors may have exerted a negative effect on the utilisation of the diary. Therefore as patients did not produce the diary due to privacy issues, forgetting it, or having trust in their doctors' ability; and professionals, in turn, did not discuss the diary as they were unsure if a patient was involved in the study or willing to share the information; then a patient could become increasingly reluctant to share their QoL diary information and their health professional could become increasingly less likely to ask for it. Ultimately the diary was seldom used.

Although the total number of patients $(n=11)$ who indicated that they had shared their diary with health care professionals was small, it was interesting that an additional six patients indicated that they shared their diary information by month four. Patients may need more time to become confident in using their diary and over time they may become prepared to share it with health professionals, with privacy becoming less of an issue as their confidence in the health care staff increased. Alternatively as their condition continued to deteriorate they decided to share the diary with the health care staff as a means of seeking help and support.

\section{Completion of diary}

Compliance rates could be considered to be quite good given that the patient group were receiving palliative care and by month four $25 \%$ had died $(n=9)$ or their condition had deteriorated to an extent that they were unable to complete the diary $(n=5)$. While some studies have shown much higher diary completion rates of 60-87\% (Caffo et al., 2003; Maunsell et al., 2000; Milligan et al., 2005; Parkin et al., 2004) it has to be highlighted that these either involved very short questionnaires (less than 10 items), over short periods of time or participants who were elderly but had no major health problems. It is well recognised that compliance varies according to the health of the patient, with it being most difficult to collect QoL data from patients with a poor status or progressive disease (Fayers, 1995). Indeed previous work in oncology has found that often large numbers of patients only complete the initial QoL assessment and do not complete subsequent assessments (Wright et al., 2003). Patients in our study may have been more willing to complete repeated measures as they were able to complete these in their own home at a time when they felt ready and able to do so. Nevertheless perhaps the completion rate could have been improved upon had there been a 'champion' in each clinical area. This person could have encouraged and enthused those patients who were poor compliers to complete their diary more frequently.

\section{Satisfaction with the diary}

Satisfaction with the diary format and layout was generally high. This is not surprising as the EORTC-QLQ-C30 has been extensively tested in similar patient populations to ensure that it is acceptable to patients and does not contain questions that could cause distress. On the negative side, some irrelevant questions were identified as 
problem areas. As the questionnaire is devised for use in all cancer groups it is understandable that some patients may find a few questions irrelevant to their personal situation. For example, patients felt that the questions relating to treatment side-effects were irrelevant if they were currently not receiving treatment.

It is interesting that over $60 \%$ of patients agreed that it was useful to complete the diary to tell health care professionals how they felt. This finding appears to contradict the earlier finding that only $23 \%$ of patients reported that they had shared their diary with the health care team. Thus while patients did not actively share the diary they found it useful in other ways. Some patients used the diary as a memory aid, others used it for reflection or to monitor their progress, whereby they are able to look back through the previous weeks of their diary and see how their QoL has changed. Positive reflection, revelation or positive life review as it is sometimes referred to, has been identified in previous studies (Hill, 2002) and has been shown to result in an increase in QoL as patients near the end of their lives. However, in our study it was apparent that not all patients found this reflection or revelation a positive experience. Negative effects of regular completion of QoL questionnaires have been identified among a small number of patients in previous studies (Greenhalgh, 2005; Hill, 2002) with the negative reflective effects being linked to a lack of feedback to clinicians (Velikova et al., 2007).

\section{Limitations}

This study has a number of limitations that should be taken into account when considering the results. Despite the absence of an upper age limit, the patients recruited were significantly younger than the general population of lung cancer patients and this may limit the generalisability of the findings.

The poor utilisation of the diary may have resulted from inadequate training and encouragement of the health care staff and patients to use the QoL diary. The value of a QoL diary in routine clinical practice was evaluated without requiring or making it compulsory for patients to share the information or the health professional to ask for it. This is possibly a flaw of the intervention, as changes in health care practice do not happen naturally but require considerable encouragement for them to be successfully implemented into routine clinical practice. Future studies should consider the importance of including training and encouragement for staff and patients when planning the implementation of a new method into clinical practice.

The pen and paper format used in this intervention, while being acceptable to patients, may have limited the health care professional's ability to read and interpret the information available. Perhaps in future studies mobile phone technology could revolutionise the collection and sharing of this information. Thought must be given to find ways of successfully collecting QoL information from patients in a user-friendly way, at a time and place that is convenient for them; processing this data to enable easy interpretation by health care professionals and ensuring that the information is then disseminated across the health care setting to all professionals involved in patient care.

\section{Conclusions}

In light of the results and discussion it can be concluded that patient compliance with the QoL diary was good, considering the high mortality and morbidity rates associated with this patient group. Patients were generally satisfied with the diary format, the time taken to complete the diary each week and the use of this format in routine care. However, the diary was not utilised as initially anticipated, as it was not shared with the entire health care team. A number of ways to overcome this problem have been discussed. Future research also needs to consider that not all patients find completion of a diary a positive experience and as Greenhalgh (2005) recommends a formal mechanism of stopping completion should be provided in any study of this nature.

\section{Acknowledgements}

We would like to thank the patients who participated in this study and the staff who provided access to patients. Thanks must also go to Dr Gordan Cran and Dr Chris Cardwell for their statistical advice and to Mrs Angela Scott for her assistance with data input.

MM was funded by a three year Research and Development Training Fellowship to carry out this study as part of a PhD. The study sponsor was Queen's University, Belfast, they had no involvement in the study design, data collection and analysis or in the writing of this manuscript.

\section{Conflict of interest Statement}

There is no conflict of interest.

\section{References}

Andersen, C., Adamsen, L., Moeller, T., Midtgaard, J., Quist, M., Tveteraas, A., et al., 2006. The effect of a multidimensional exercise programme on symptoms and side-effects in cancer patients undergoing chemotherapy - the use of semistructured diaries. European Journal of Oncology Nursing 104, 247-262.

Basch, E., Iasonos, A., Barz, A., Culkin, A., Kris, M.G., Artz, D., et al., 2007. Long-term toxicity monitoring via electronic patient-reported outcomes in patients receiving chemotherapy. Journal of Clinical Oncology 2534, 5374-5380.

Bergman, B., Aaronson, N.K., Ahmedzai, S., Kaasa, S., Sullivan, M., 1994. The EORTC QLQ-LC13: a modular supplement to the EORTC core quality of life questionnaire QLQ-C30 for use in lung cancer clinical trials. EORTC study group on quality of life. European Journal of Cancer 30A5, 635-642.

Bottomley, A., Efficace, F., Thomas, R., Vanvoorden, V., Ahmedzai, S.H., 2003. Healthrelated quality of life in non-small-cell lung cancer: methodologic issues in randomized controlled trials. Journal of Clinical Oncology 2115, 2982-2992.

Boyes, A., Newell, S., Girgis, A., McElduff, P., Sanson-Fisher, R., 2006. Does routine assessment and real-time feedback improve cancer patients' psychosocial wellbeing? European Journal of Cancer Care 15, 163-171.

Caffo, O. Amichetti, M., Mussari, S., Romano, M., Maluta, S., Tomio, L, et al, 2003. Physical side effects and quality of life during postoperative radiotherapy for uterine cancer. Prospective evaluation by a diary card. Gynecologic Oncology $883,270-276$

Cooley, M.E., Sarna, L., Brown, J.K., Williams, R.D., Chernecky, C., Padilla, G., et al., 2003. Challenges of recruitment and retention in multisite clinical research. Cancer Nursing 265, 376-384.

Detmar, S.B., Aaronson, N.K., Wever, L.D., Muller, M., Schornagel, J.H., 2000. How are you feeling? Who wants to know? Patients' and oncologists' preferences for discussing health-related quality-of-life issues. Journal of Clinical Oncology 1818, 3295-3301.

Detmar, S.B., Muller, M.J., Schornagel, J.H., Wever, L.D.V., Aaronson, N.K., 2002 Health-related quality-of-life assessments and patient-physician communication - a randomized controlled trial. JAMA-Journal of the American Medical Association 28823, 3027-3034.

Efficace, F., Biganzoli, L., Piccart, M., Coens, C., Van Steen, K., Cufer, T., et al., 2004 Baseline health-related quality-of-life data as prognostic factors in a phase III multicentre study of women with metastatic breast cancer. European Journal of Cancer 407, 1021-1030.

Efficace, F., Bottomley, A., Coens, C., Van Steen, K., Conroy, T., Schoffski, P., et al., 2006. Does a patient's self-reported health-related quality of life predict survival beyond key biomedical data in advanced colorectal cancer? European Journal of Cancer 421, 42-49.

Espallargues, M., Valderas, J.M., Alonso, J., 2000. Provision of feedback on perceived health status to health care professionals: a systematic review of its impact Medical Care 382, 175-186.

Fayers, P., 1995. MRC quality of life studies using a daily diary card - practical lessons learned from cancer trials. Quality of Life Research 44, 343-352.

Frost, M.H., Bonomi, A.E., Cappelleri, J.C., Schunemann, H.J., Moynihan, T.J. Aaronson, N.K., et al., 2007. Applying quality-of-life data formally and systematically into clinical practice. Mayo Clinic Proceedings 8210, 1214-1228.

Ganz, P.A., Lee, J.J., Siau, J., 1991. Quality of life assessment: an independent prognostic variable for survival in lung cancer. Cancer 6712, 3131-3135.

Geddes, D.M., Dones, L., Hill, E., Law, K., Harper, P.G., Spiro, S.G., et al., 1990. Quality of life during chemotherapy for small cell lung cancer: assessment and use of a daily diary card in a randomized trial. European Journal of Cancer 264, 484-492.

Greenhalgh, J., 2005. An assessment of the feasibility and utility of the MS symptom and impact diary MSSID. Quality of Life Research 145, 1363-1374. 
Greenhalgh, J., Long, A.F., Flynn, R., 2005. The use of patient reported outcome measures in routine clinical practice: lack of impact or lack of theory? Social Science and Medicine 604, 833-843.

Hahn, E.A., Cella, D., 2003. Health outcomes assessment in vulnerable populations: measurement challenges and recommendations. Archives of Physical Medicine and Rehabilitation 844, S35-S42.

Haywood, K., Marshall, S., Fitzpatrick, R., 2006. Patient participation in the consultation process: a structured review of intervention strategies. Patient Education and Counseling 631-632, 12-23.

Hicsonmez, A., Kose, K., Andrieu, M.N., Guney, Y., Kurtman, C., 2007. The European Organization for Research and Treatment of Cancer core quality of life questionnaire QLQ-C30 version 3.0 Turkish in cancer patients receiving palliative radiotherapy. European Journal of Cancer Care 163, 251-257.

Hill, N., 2002. Use of quality-of-life scores in care planning in a hospice setting: the theme of revelation. International Journal of Palliative Nursing 812, 591593.

Hjermstad, M.J., Fossa, S.D., Bjordal, K., Kaasa, S., 1995. Test/retest study of the European Organization for Research and Treatment of cancer core quality-oflife questionnaire. Journal of Clinical Oncology 135, 1249-1254.

Hoekstra, J., Bindels, P.J., van Duijn, N.P., Schade, E., 2004. The symptom monitor. A diary for monitoring physical symptoms for cancer patients in palliative care: feasibility, reliability and compliance. Journal of Pain and Symptom Management 271, 24-35.

Hyland, M.E., Crocker, G.R., 1995. Validation of an asthma quality of life diary in a clinical trial. Thorax 507, 724-730.

Ishihara, Y., Sakai, H., Nukariya, N., Kobayashi, K., Yoneda, S., Matsuoka, R., et al., 1999. A diary form quality of life questionnaire for Japanese patients with lung cancer and summarization techniques for longitudinal assessment. Respirology 41, 53-61.

Lecouturier, J., Crack, L., Mannix, K., Hall, R.H., Bond, S., 2002. Evaluation of a patient-held record for patients with cancer. European Journal of Cancer Care $112,114-121$

Ling, J., Rees, E., Hardy, J., 2000. What influences participation in clinical trials in palliative care in a cancer centre? European Journal of Cancer 365, 621-626.

Maunsell, E., Allard, P., Dorval, M., Labbe, J., 2000. A brief pain diary for ambulatory patients with advanced cancer: acceptability and validity. Cancer 8810, 2387-2397.

Mazonson, P.D., Mathias, S.D., Fifer, S.K., Buesching, D.P., Malek, P., Patrick, D.L. 1996 The mental health patient profile: does it change primary care physicians practice patterns? The Journal of the American Board of Family Practice 95, 336-345.

McLachlan, S.A., Allenby, A., Matthews, J., Wirth, A., Kissane, D., Bishop, M., et al., 2001. Randomized trial of coordinated psychosocial interventions based on patient self-assessments versus standard care to improve the psychosocial functioning of patients with cancer. Journal of Clinical Oncology 1921, 4117-4125.

Milligan, C., Bingley, A., Gatrell, A., 2005. Digging deep: using diary techniques to explore the place of health and well-being amongst older people. Social Science and Medicine 619, 1882-1892.

Montazeri, A., Milroy, R., Hole, D., McEwen, J., Gillis, C.R., 2001. Quality of life in lung cancer patients: as an important prognostic factor. Lung Cancer 312, 233-240.
Morris, J., Perez, D., McNoe, B., 1998. The use of quality of life data in clinical practice. Quality of Life Research 71, 85-91.

Nicklasson, M., Bergman, B., 2007. Validity, reliability and clinical relevance of EORTC QLQ-C30 and LC13 in patients with chest malignancies in a palliative care setting. Quality of Life Research 1610, 1019-1028.

Osoba, D., 1999. What has been learned from measuring health-related quality of life in clinical oncology. European Journal of Cancer 3511, 1565-1570.

Ouslander, J.G., 2007. Quality improvement initiatives for urinary incontinence in nursing homes. JAMA-Journal of the American Medical Association 83 (Suppl.), S6-S11.

Parkin, D., Rice, N., Jacoby, A., Doughty, J., 2004. Use of a visual analogue scale in a daily patient diary: modelling cross-sectional time-series data on healthrelated quality of life. Social Science and Medicine 592, 351-360.

Perry, S., Kowalski, T.L., Chang, C.H., 2007. Quality of life assessment in women with breast cancer: benefits, acceptability and utilization. Health and Quality of Life Outcomes 5, 24

Reid, K., Asbury, J., MacDonald, R., Serpell, M., 2003. Putting pain to paper: a qualitative study of chronic pain patients' experiences of using a two-week selfreport pain diary. Health Psychology Update 124, 13

Roth, L.M., Neale, A.V., Kennedy, K., DeHaven, M.J., 2007. Insights from practicebased researchers to develop family medicine faculty as scholars. Family Medicine 397, 504-509.

Rubenstein, L.V. McCoy, J.M., Cope, D.W., Barrett, P.A, Hirsch, S.H., Messer, K.S, et al. 1995. Improving patient quality of life with feedback to physicians about functional status. Journal of General Internal Medicine 1011, 607-614.

Schachter, K.A., Cohen, S.J., 2005. From research to practice: challenges to implementing national diabetes guidelines with five community health centers on the U.S.-Mexico border. Preventing Chronic Disease 21, A17.

Shafer, M.A., Tebb, K.P., Pantell, R.H., Wibbelsman, C.J., Neuhaus, J.M., Tipton, A.C., et al., 2002. Effect of a clinical practice improvement intervention on chlamydial screening among adolescent girls. JAMA-Journal of the American Medical Association 28822, 2846-2852.

Taenzer, P., Bultz, B.D., Carlson, L.E., Speca, M., DeGagne, T., Olson, K., et al., 2000. Impact of computerized quality of life screening on physician behaviour and patient satisfaction in lung cancer outpatients. Psycho-oncology 93, 203-213.

Velikova, G., Brown, J.M., Smith, A.B., Selby, P.J., 2002. Computer-based quality of life questionnaires may contribute to doctor-patient interactions in oncology. British Journal of Cancer 861, 51-59.

Velikova, G., Awad, N., Smith, A.B., Campbell, L., Sheppard, S., Selby, P.J., 2007. Regular quality of life measurement during cancer chemotherapy - do oncologists need to know? Paper presented at the International Society of Quality of Life Research Conference, Toronto, Canada, A-10 (Abstract \# 1756).

Velikova, G., Booth, L., Smith, A.B., Brown, P.M., Lynch, P., Brown, J.M., et al., 2004. Measuring quality of life in routine oncology practice improves communication and patient well-being: a randomized controlled trial. Journal of Clinical Oncology 224, 714-724.

Wright, E.P., Selby, P.J., Crawford, M., Gillibrand, A., Johnston, C., Perren, T.J., et al., 2003. Feasibility and compliance of automated measurement of quality of life in oncology practice. Journal of Clinical Oncology 212, 374-382. 